\title{
The influence of left ventricular pacing polarity on ventricular repolarization parameters in cardiac resynchronization therapy and its clinical reflections on ventricular tachyarrhythmias
}

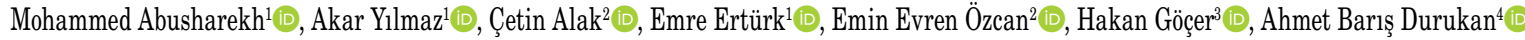

${ }^{1}$ Department of Cardiology, Izmir University of Economics, Faculty of Medicine, Izmir, Turkey

${ }^{2}$ Department of Cardiology, Dokuz Eylül University, Faculty of Medicine, Izmir, Turkey

${ }^{3}$ Department of Cardiology, Edremit Körfez Hospital, Balıkesir, Turkey

${ }^{4}$ Department of Cardiovascular Surgery, Salihli Private Medigüneş Hospital, Manisa, Turkey

Received: February 08, 2021 Accepted: February 20, 2021 Published online: March 29, 2021

\begin{abstract}
Objectives: This study aims to investigate the effects of the left ventricular (LV) pacing polarities on ventricular repolarization patterns and to examine novel parameters taking depolarization into account.

Patients and methods: This prospective study included a total of 54 patients ( 39 males, 15 females; mean age: $65.2 \pm 11.6$ years; range, 40 to 89 years) with successful cardiac resynchronization therapy using quadripolar LV leads between January 2014 and February 2017. The patients were divided into two groups as the true bipolar group $(n=25)$ and the unipolar/extended bipolar group ( $n=29)$. Ventricular repolarization parameters and novel markers, i.e., TpTe/QRS, Tpec/QRS, TpTe/(QRS $\times$ QTc) and Tpec/(QRS $\times$ QTc), were measured before implantation within $48 \mathrm{~h}$ following the procedure and at six months. Evaluation of ventricular tachyarrhythmias was performed using device records during follow-up.

Results: The median follow-up was 17.7 (range, 12.6 to 31.2 ) months. The mean ejection fraction was $23.3 \pm 5.5 \%$ in the bipolar group and $23.62 \pm 6.24 \%$ in the unipolar/extended bipolar group. Bipolar LV pacing was associated with higher Tpec/QTc values (acute, bipolar vs. unipolar, +0.011 vs. $-0.0008, p=0.019$; long-term, bipolar vs. unipolar, +0.005 vs. $-0.015, p=0.005$, respectively). There was no significant difference between the groups in terms of other repolarization parameters. Bipolar pacing was associated with significantly higher novel markers values and more frequent sustained and non-sustained ventricular tachyarrhythmias.

Conclusion: The LV pacing polarity significantly affects Tpec/QTc, but not the other ventricular repolarization parameters. Novel arrhythmia predictors, i.e., TpTe/QRS, Tpec/QRS, TpTe/(QRS x QTc), and Tpec/(QRS x QTc), are more influenced in bipolar pacing associated with more frequent ventricular tachyarrhythmias.

Keywords: Cardiac resynchronization therapy, depolarization, pacing polarity, tachycardia, ventricular.
\end{abstract}

Despite enormous advances in pharmacological treatments in recent years, heart failure (HF) continues to occupy an important place among the leading causes of morbidity and mortality. Cardiac resynchronization therapy (CRT), which has created an important glimmer of hope in this regard, has become an established treatment procedure to improve clinical complaints and exercise tolerance, and to reduce all-cause mortality and hospitalizations in patients with mild-to-severe HF, reduced left ventricular (LV) systolic functions, and wide QRS complex, particularly with left bundle branch block (LBBB) morphology. ${ }^{[1]}$ Reverse remodeling and ventricular resynchronization are mechanisms of action of CRT. To correct these intra- and interventricular contraction disorders, three leads are placed in the right atrium, right ventricular apex, and LV epicardial surface (either retrograde via the coronary sinus [CS] or surgically). Consequently, cardiac output increases, pulmonary capillary wedge pressure decreases, and contractility is improved..$^{[2,3]}$

Providing different vector activation of different pacing configurations can affect ventricular

Corresponding author: Ahmet Barıș Durukan, MD. Özel Medigüneș Hastanesi Kalp ve Damar Cerrahisi Bölümü, 45300 Salihli, Manisa, Türkiye.

Tel: +90 532 - 2273814 e-mail: barisdurukan@yahoo.com

\section{Citation:}

Abusharekh M, Yılmaz A, Alak Ç, Ertürk E, Özcan EE, Göçer H, et al. The influence of left ventricular pacing polarity on ventricular repolarization parameters in cardiac resynchronization therapy and its clinical reflections on ventricular tachyarrhythmias. Cardiovasc Surg Int 2021;8(1):44-52. 
repolarization patterns. Quadripolar LV leads exhibit 10 variant pacing configurations in the clinical practice, although LV lead pacing polarity is mostly a modifiable parameter. Preference of pacing configuration is made taking into account the branch of the available CS, the risk of phrenic nerve stimulation, and optimization of LV pacing thresholds, whereas unipolar stimulation can be placed between the tip and generator, or between the pacing tip and the right ventricular coil or ring electrode (known as extended bipolar), Bipolar stimulation can be between distal and proximal electrodes or vice versa. ${ }^{[4]}$

Differences in mechanical activation sequence according to pacing polarities have been proven, resulting in different activation between the different layers of the myocardium, and this affect the ventricular repolarization patterns. ${ }^{[5]}$ The difference in intrinsic repolarization between epicardium, midmyocardial $\mathrm{M}$ cells, and endocardium varies according to $\mathrm{LV}$ pacing polarities. Additionally, as a result of delayed activation and repolarization of midmyocardial $M$ cells during epicardial biventricular pacing, the transmural dispersion of repolarization (TDR) can be significantly increased. ${ }^{[6]}$ In the light of this knowledge, the influences of $L V$ pacing polarity on ventricular repolarization parameters and its relationship with the likelihood of developing ventricular arrhythmias has become a matter of concern.

Potential proarrhythmic effects of CRT are still controversial and various mechanisms have been proposed. One of the main mechanisms is the reversal of the myocardial activation sequence, which increases QT and TDR. ${ }^{[7]}$ Furthermore, it has been suggested that the proarrhythmic mechanism of unidirectional block and re-entry may be corrected by changing the activation sequence within the scar areas. ${ }^{[8]}$ In contrast, antiarrhythmic properties of CRT are advocated by leading to LV reverse remodeling, electrical stabilization of myocyte membranes, and bringing about a decrease in myocardial wall stress. ${ }^{[9]}$

It has been previously documented that long-term clinical outcomes of different LV pacing polarity, unipolar/extended bipolar configuration are associated with a higher incidence of $\mathrm{HF} /$ death, and all-cause mortality in patients with LBBB, compared to true bipolar. ${ }^{[10]}$ Although the effect on ventricular repolarization patterns has not been studied, no significant difference is observed in terms of ventricular tachyarrhythmic (VTA) events. ${ }^{[10]}$ In our study, we aimed to investigate the effects of different LV pacing polarities on ventricular repolarization patterns and to examine the novel arrhythmia predictive parameters taking depolarization into account and its relationship with VTA events.

\section{PATIENTS AND METHODS}

This single-center, prospective study was conducted at Dokuz Eylül University, Department of Cardiology and Medical Park Izmir Hospital, Department of Cardiology between January 2014 and February 2017. A total of 54 patients ( 39 males, 15 females; mean age: $65.2 \pm 11.6$ years; range, 40 to 89 years) with successful CRT with biventricular pacemaker implantation using quadripolar LV leads according to the conventional CRT indications were included in the study. The only indication for CRT-defibrillator (D) implantation was considered the primary prevention from sudden cardiac death (SCD). Inclusion criteria were as follows: (i) patients with a standard indication of CRT according to the New York Heart Association (NYHA) Class II-IV despite optimal medical therapy with a LV ejection fraction (LVEF) of $\leq 35 \%$ and a QRS duration of $>130 \mathrm{msec}$, irrespective of the QRS morphology; and (ii) patients with a LVEF of $\leq 35 \%$ regardless of the NYHA functional class who required ventricular pacing and had a CRT indication due to a QRS duration of $>130 \mathrm{msec}$, irrespective of the QRS morphology. Exclusion criteria were as follows: patients with a QRS duration of $<130 \mathrm{msec}$, a history of ventricular arrhythmia event or SCD according to medical history and Holter electrocardiographic [ECG] records, Wolff-Parkinson-White (WPW) syndrome, arrhythmogenic right ventricular dysplasia, Brugada syndrome, or a history of channelopathy, failure of the CS cannulation or implantation procedure. A written informed consent was obtained from each patient. The study protocol was approved by the Dokuz Eylül University, School of Medicine, Ethics Committee (date/no: 16.11.2016-61804747000/1056). The study was conducted in accordance with the principles of the Declaration of Helsinki.

The CRT-D device implantation and identifying the LV pacing configurations in terms of polarity were performed in the cardiac catheterization laboratory using standard transvenous approach of CRT device implantation techniques. Following an apically right ventricular shock lead implantation, a quadripolar LV (The Quartet Model 1458Q, St. Jude Medical, St. 
Paul, Minnesota, USA) and the right atrium leads were implanted, respectively, and capture thresholds were recorded simultaneously. The identification of LV electrodes was determined as the Distal 1(D1), Mid 2(M2), Mid 3(M3), and Proximal 4(P4), respectively, starting from the distal tip electrode. Then different pacing configurations offered by the quadripolar LV lead were defined as follows: True Bipolar: D1 to M2, D1 to P4, M2 to P4, M3 to M2, $\mathrm{M} 3$ to P4 and P4 to M2 configurations; Unipolar (or extended bipolar): D1 to RV coil, M2 to RV coil, M3 to RV coil and $\mathrm{P} 4$ to $\mathrm{RV}$ coil configurations (Figure 1). The patients were divided into two groups as the true bipolar group $(n=25)$ and the unipolar/extended bipolar group $(\mathrm{n}=29)$.

The 12-lead ECGs were recorded before CRT device implantation within $48 \mathrm{~h}$ following the procedure and six months after the procedure. All ECGs were scanned digitally and evaluation was made at $400 \%$ magnification. The measurements were performed by a blinded cardiologist. The onset of the QT interval was determined as the first portion (deflection) of the QRS complex, and the end was identified as the point where the isoelectric line intersected the tangent slope of the $T$ wave. The longest interval of entire leads wherein the $\mathrm{T}$ wave was obviously selected (usually V2 or V3) was regarded to be the $\mathrm{QT}$ interval. The acquired $\mathrm{QT}$ value was corrected to heart rate using the Bazzet formula (QTc). The QT peak interval was defined as

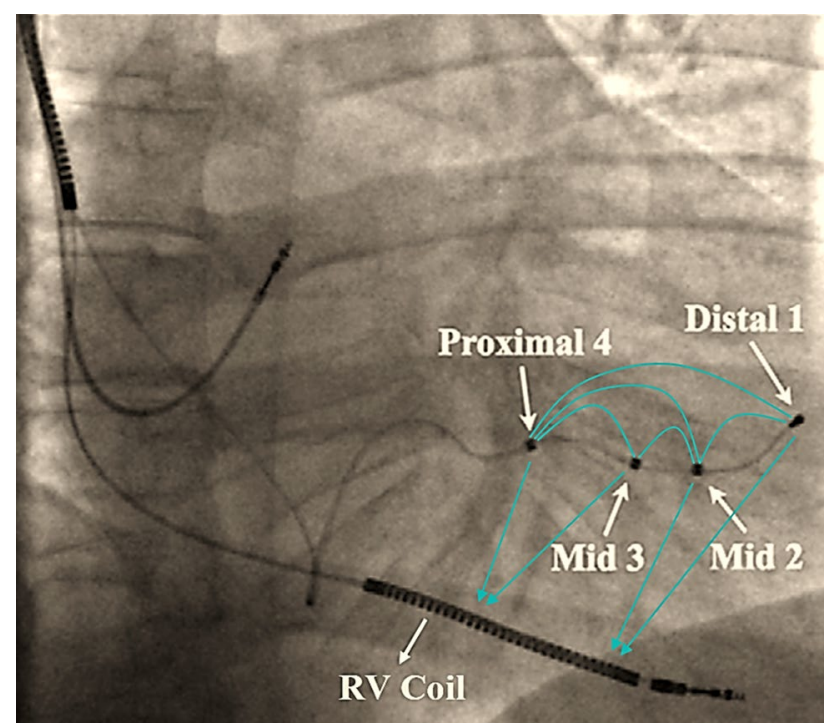

Figure 1. Cardiac fluoroscopic image showing bipolar stimulation. the interval from the onset of the QRS to the peak of the positive $\mathrm{T}$ wave or the bottom of a negative $\mathrm{T}$ wave. In case of a biphasic $\mathrm{T}$ wave, the first peak was selected as a reference point for measurement. The TpTe interval was calculated by subtracting the QT peak interval from the QT interval. TpTe was averaged after measuring TpTe in all 12 leads. The TpTe value was corrected according to the Bazzet formula and Tpec was obtained. The QT and TpTe dispersions were calculated from the difference between the longest and shortest of the mentioned intervals in 12-lead ECG. The TpTe/QT, Tpec/ QTc, TpTe/QRS, Tpec/QRS, TpTe/(QRS $\times$ QTc), $\mathrm{Tpec} /(\mathrm{QRS} \times \mathrm{QTc})$ values were also calculated..$^{[11]}$

Evaluation of VTA events was performed based on the recorded ECG readings and clinical records. Device therapies were analyzed in two main categories as anti-tachycardic pacing (ATP) or shock. In case of both ATP and shock delivery in the same arrhythmia episode, the episode was evaluated in the shock category. Ventricular tachyarrhythmia detected by the device and terminated spontaneously without any therapy was recognized as non-sustained ventricular tachycardia (NSVT). Ventricular tachycardia (VT) or ventricular fibrillation (VF) episodes which met the device detection criteria and underwent therapy (ATP or shock) were considered to be sustained VTAs. Electrical storm was defined as $\geq 3$ VTA episodes within $24 \mathrm{~h}$. Tachyarrhythmic events treated by the device as a result of atrial fibrillation (AF) or supraventricular tachycardia (SVT) were identified as inappropriate and not included in the analysis. The VTA detection criteria of the device and therapy settings were programmed in accordance with the nominal settings at the time of implantation and, if necessary, changed only at the discretion of the cardiologist.

\section{Statistical analysis}

Statistical analysis was performed using the PASW 17.0 software (SPSS Inc., Chicago, IL, USA). Continuous variables were presented in mean \pm standard deviation (SD) or median (interquartile range [IQR], while categorical variables were presented in number and frequency. For the comparison of independent variables with the dependent variables, the Mann-Whitney U test was used, since non-parametric conditions were provided for numerical variables. The chi-square test was used to compare categorical variables. A $p$ value of $<0.05$ was considered statistically significant. 


\section{RESULTS}

The median follow-up was 17.7 (range, 12.6 to 31.2) months. The mean age was $64.7 \pm 12.3$ in the true bipolar group and $65.7 \pm 11.2$ in the unipolar/extended bipolar group. The mean LVEF was $23.3 \pm 5.5 \%$ in the true bipolar group and $23.6 \pm 6.2 \%$ in the unipolar/ extended bipolar group. The baseline characteristics of both groups were comparable (Table 1).

To analyze the difference acute effects of CRT on ventricular repolarization parameters and the novel arrhythmia markers between the groups, preprocedural ECGs were compared to ECGs at $48 \mathrm{~h}$ after CRT device implantation. Compared to the pre-procedural values, an increase in the TpTe/QRS, Tpec/QRS, TpTe/(QRS $\times$ QT) and Tpec/(QRS x QTc) values in the acute period was more prominent in the bipolar group $(p=0.026, p=0.018, p=0.016$, and $\mathrm{p}=0.013$, respectively). The TpTe/QT and Tpec/QTc values were found to be acutely increased after the procedure in the bipolar group, while a decrease was observed in the unipolar group $(p=0.089$ and $p=0.019$,

\begin{tabular}{|c|c|c|c|c|c|c|c|}
\hline \multicolumn{8}{|c|}{$\begin{array}{c}\text { Table } 1 \\
\text { Baseline demographic and clinical characteristics of study population }\end{array}$} \\
\hline & \multicolumn{3}{|c|}{ True bipolar $(\mathrm{n}=25)$} & \multicolumn{3}{|c|}{ Unipolar/extended bipolar $(n=29)$} & \multirow[b]{2}{*}{$p$} \\
\hline & $\mathrm{n}$ & $\%$ & Mean \pm SD & $\mathrm{n}$ & $\%$ & Mean \pm SD & \\
\hline Age (year) & & & $64.7 \pm 12.3$ & & & $65.7 \pm 11.2$ & 0.755 \\
\hline LVEF (\%) & & & $23.3 \pm 5.5$ & & & $23.6 \pm 6.2$ & 0.853 \\
\hline $\mathrm{DM}$ & 7 & 28 & & 8 & 27.58 & & 0.973 \\
\hline $\mathrm{HT}$ & 8 & 32 & & 9 & 31 & & 0.939 \\
\hline Sex & & & & & & & 0.565 \\
\hline Male & 19 & 76 & & 20 & 69 & & \\
\hline Female & 6 & 24 & & 9 & 31 & & \\
\hline Etiology & & & & & & & 0.542 \\
\hline Ischemic & 10 & 40 & & 14 & 48 & & \\
\hline Non-ischemic & 15 & 60 & & 15 & 52 & & \\
\hline NYHA Class & & & & & & & 0.567 \\
\hline I-II & - & - & & 1 & 3.44 & & \\
\hline II & - & - & & 1 & 3.44 & & \\
\hline II-III & 1 & 4 & & 3 & 10.34 & & \\
\hline III & 22 & 88 & & 21 & 72.41 & & \\
\hline Ambulatory IV & 2 & 8 & & 3 & 10.34 & & \\
\hline Baseline rhythm & & & & & & & 0.499 \\
\hline $\mathrm{AF}$ & 2 & 8 & & 4 & 13.8 & & \\
\hline SR & 23 & 92 & & 25 & 86.2 & & \\
\hline QRS morphology & & & & & & & 0.560 \\
\hline LBBB & 24 & 96 & & 28 & 96.55 & & \\
\hline RBBB & 1 & 4 & & 1 & 3.44 & & \\
\hline \multicolumn{8}{|l|}{ Device } \\
\hline CRT-D & 25 & 100 & & 29 & 100 & & \\
\hline CRT-P & - & & & - & & & \\
\hline \multicolumn{8}{|l|}{ Drugs } \\
\hline ACE-I/ARB & 23 & 92 & & 26 & 89.65 & & 0.893 \\
\hline Beta blocker & 24 & 96 & & 28 & 96.55 & & 1.000 \\
\hline MRA & 14 & 56 & & 17 & 58.62 & & 0.923 \\
\hline Amiodarone & 13 & 52 & & 8 & 27.58 & & 0.067 \\
\hline Digoxin & 5 & 20 & & 2 & 6.89 & & 0.229 \\
\hline
\end{tabular}


respectively). We revealed no statistically significant difference in the QRS duration between the groups (median: -18.66 vs. -13.22 msec, respectively; $\mathrm{p}=0.515$ ). When the early changes in other ECG parameters were compared, no statistically significant difference was revealed according to the $\mathrm{LV}$ pacing polarity (Table 2).

Statistically significant differences in the LV pacing polarity between the groups persisted at six months; however, there was a marked decline in the median values of ventricular repolarization parameters and novel markers, compared to the acute phase. Compared to the pre-procedural values, the increase in the TpTe/QRS, Tpec/QRS, TpTe/(QRS $\times \mathrm{QT})$ and
Tpec/(QRS $\times$ QTc) values at six months was higher in the bipolar group $(\mathrm{p}=0.023, \mathrm{p}=0.004, \mathrm{p}=0.052$, and $\mathrm{p}=0.006$, respectively). Although the median value of Tpec/QTc decreased compared to the acute phase, the increase from baseline persisted at six months in the bipolar group, while a decrease from baseline was observed in the unipolar/extended bipolar group (bipolar vs. unipolar: +0.005 vs. -0.015 , respectively; $\mathrm{p}=0.005)$. At six months, no statistically significant difference in the QRS duration was revealed between the groups (median: -20.10 vs. -13.59 , respectively; $\mathrm{p}=0.302$ ). When the long-term changes in other ECG parameters were compared, no statistically significant difference was revealed according to the LV pacing

\begin{tabular}{|c|c|c|c|c|}
\hline \multicolumn{5}{|c|}{$\begin{array}{c}\text { Table } 2 \\
\text { Electrocardiographic changes in acute period based on left ventricular pacing polarity }\end{array}$} \\
\hline Electrocardiographic measurements & Polarity & Median & Interquartile range & $p^{*}$ \\
\hline \multirow{2}{*}{$\Delta^{1-2} \mathrm{TpTe}$ interval (ms) } & Unipolar & +11.08 & 46.49 & \multirow{2}{*}{0.147} \\
\hline & Bipolar & +13.83 & 22.47 & \\
\hline \multirow{2}{*}{$\Delta^{1-2}$ Tpec (ms) } & Unipolar & +7.59 & 41.62 & \multirow{2}{*}{0.125} \\
\hline & Bipolar & +16.12 & 19.85 & \\
\hline \multirow{2}{*}{$\Delta^{1-2} \mathrm{TpTe}$ dispersion $(\mathrm{ms})$} & Unipolar & +12.95 & 58.62 & \multirow{2}{*}{0.855} \\
\hline & Bipolar & +10.44 & 49.02 & \\
\hline \multirow{2}{*}{$\Delta^{1-2} \mathrm{QTc}(\mathrm{ms})$} & Unipolar & +52.00 & 105.07 & \multirow{2}{*}{0.931} \\
\hline & Bipolar & +38.95 & 54.67 & \\
\hline \multirow{2}{*}{$\Delta^{1-2} \mathrm{Tp}-\mathrm{Te} / \mathrm{QT}$} & Unipolar & -0.006 & 0.05 & \multirow{2}{*}{0.089} \\
\hline & Bipolar & +0.012 & 0.04 & \\
\hline \multirow{2}{*}{$\Delta^{1-2} \mathrm{Tpec} / \mathrm{QTc}$} & Unipolar & -0.0008 & 0.04 & \multirow{2}{*}{0.019} \\
\hline & Bipolar & +0.011 & 0.03 & \\
\hline \multirow{2}{*}{$\Delta^{1-2}$ QRS duration (ms) } & Unipolar & -13.22 & 23.66 & \multirow{2}{*}{0.515} \\
\hline & Bipolar & -18.66 & 15.12 & \\
\hline \multirow{2}{*}{$\Delta^{1-2}$ QT dispersion (ms) } & Unipolar & +21.98 & 46.94 & \multirow{2}{*}{0.391} \\
\hline & Bipolar & +33.85 & 42.42 & \\
\hline \multirow{2}{*}{$\Delta^{1-2}(\mathrm{TpTe}) / \mathrm{QRS}$} & Unipolar & +0.08 & 0.25 & \multirow{2}{*}{0.026} \\
\hline & Bipolar & +0.15 & 0.13 & \\
\hline \multirow{2}{*}{$\Delta^{1-2}(\mathrm{Tpec}) / \mathrm{QRS}$} & Unipolar & +0.12 & 0.25 & \multirow{2}{*}{0.018} \\
\hline & Bipolar & +0.17 & 0.18 & \\
\hline \multirow{2}{*}{$\Delta^{1-2}(\mathrm{Tpec}) /(\mathrm{QRS} \times \mathrm{QTc})\left(\mathrm{ms}^{-1}\right)$} & Unipolar & $+1 * 10-4$ & 0.00 & \multirow{2}{*}{0.013} \\
\hline & Bipolar & $+2 * 10-4$ & 0.00 & \\
\hline \multirow{2}{*}{$\Delta^{1-2}(\mathrm{TpTe}) /(\mathrm{QRS} \times \mathrm{QTc})\left(\mathrm{ms}^{-1}\right)$} & Unipolar & $+1 * 10-4$ & 0.00 & \multirow{2}{*}{0.016} \\
\hline & Bipolar & $+2 * 10-4$ & 0.00 & \\
\hline
\end{tabular}




\begin{tabular}{|c|c|c|c|c|}
\hline \multicolumn{5}{|c|}{$\begin{array}{c}\text { Table } 3 \\
\text { Electrocardiographic changes in long-term based on left ventricular pacing polarity }\end{array}$} \\
\hline Electrocardiographic measurements & Polarity & Median & Interquartile range & $p^{*}$ \\
\hline \multirow{2}{*}{$\Delta^{1-3} \mathrm{TpTe}$ interval (ms) } & Unipolar & -6.05 & 35.63 & \multirow{2}{*}{0.196} \\
\hline & Bipolar & +6.21 & 28.15 & \\
\hline \multirow{2}{*}{$\Delta^{1-3} \mathrm{Tpec}(\mathrm{ms})$} & Unipolar & -3.02 & 35.04 & \multirow{2}{*}{0.075} \\
\hline & Bipolar & +5.71 & 26.88 & \\
\hline \multirow{2}{*}{$\Delta^{1-3} \mathrm{TpTe}$ dispersion (ms) } & Unipolar & +9.99 & 57.72 & \multirow{2}{*}{0.472} \\
\hline & Bipolar & +0.81 & 29.81 & \\
\hline \multirow{2}{*}{$\Delta^{1-3} \mathrm{QTc}(\mathrm{ms})$} & Unipolar & -1 & 81.80 & \multirow{2}{*}{0.952} \\
\hline & Bipolar & +4 & 59.77 & \\
\hline \multirow{2}{*}{$\Delta^{1-3} \mathrm{Tp}-\mathrm{Te} / \mathrm{QT}$} & Unipolar & -0.014 & 0.02 & \multirow{2}{*}{0.062} \\
\hline & Bipolar & -0.004 & 0.03 & \\
\hline \multirow{2}{*}{$\Delta^{1-3} \mathrm{Tpec} / \mathrm{QTc}$} & Unipolar & -0.015 & 0.02 & \multirow{2}{*}{0.005} \\
\hline & Bipolar & +0.005 & 0.03 & \\
\hline \multirow{2}{*}{$\Delta^{1-3}$ QRS duration (ms) } & Unipolar & -13.59 & 22.13 & \multirow{2}{*}{0.302} \\
\hline & Bipolar & -20.10 & 16.77 & \\
\hline \multirow{2}{*}{$\Delta^{1-3} \mathrm{QT}$ dispersion (ms) } & Unipolar & -2.86 & 31.58 & \multirow{2}{*}{0.788} \\
\hline & Bipolar & +2.96 & 29.43 & \\
\hline \multirow{2}{*}{$\Delta^{1-3}(\mathrm{TpTe}) / \mathrm{QRS}$} & Unipolar & +0.03 & 0.13 & \multirow{2}{*}{0.023} \\
\hline & Bipolar & +0.08 & 0.14 & \\
\hline \multirow{2}{*}{$\Delta^{1-3}(\mathrm{Tpec}) / \mathrm{QRS}$} & Unipolar & +0.03 & 0.16 & \multirow{2}{*}{0.004} \\
\hline & Bipolar & +0.12 & 0.14 & \\
\hline \multirow{2}{*}{$\Delta^{1-3}(\mathrm{Tpec}) /(\mathrm{QRS} \times \mathrm{QTc})\left(\mathrm{ms}^{-1}\right)$} & Unipolar & 0 & 0.00 & \multirow{2}{*}{0.006} \\
\hline & Bipolar & $+2 * 10-4$ & 0.00 & \\
\hline \multirow{2}{*}{$\Delta^{1-3}(\mathrm{TpTe}) /(\mathrm{QRS} \times \mathrm{QTc})\left(\mathrm{ms}^{-1}\right)$} & Unipolar & 0 & 0.00 & \multirow{2}{*}{0.052} \\
\hline & Bipolar & $+2 * 10-4$ & 0.00 & \\
\hline \multicolumn{5}{|c|}{$\begin{array}{l}{ }^{*} \text { Mann Whitney U test; } \Delta^{1-3} \text { : Change between before and long term after the procedure (at } 6 \text { month); QTc: QT interval corrected } \\
\text { according to the Bazzet formula; TpTe: Difference between QT and QT peak interval; Tpec: TpTe interval corrected according to } \\
\text { the Bazzet formula. }\end{array}$} \\
\hline
\end{tabular}

polarity (Table 3). Figure 2 shows the acute and long-term difference of CRT's impact on Tpec/QRS according to $\mathrm{LV}$ pacing polarity, as an example of novel arrhythmia markers.

Considering VTAs, we observed that both sustained and NSVTs were higher in the true bipolar group. A detailed analysis revealed that sustained VTAs were observed in 22 patients, 14 (63.6\%) of which were bipolar and eight (36.4\%) were unipolar $(\mathrm{p}=0.034)$. Similarly, NSVTs were found to be significantly higher in the true bipolar group (73.7\%), whereas $26.3 \%$ were in the unipolar group ( $\mathrm{p}=0.003)$. In terms of $\mathrm{VF}$, there was no significant difference between the groups $(p=0.313)$. Furthermore, there

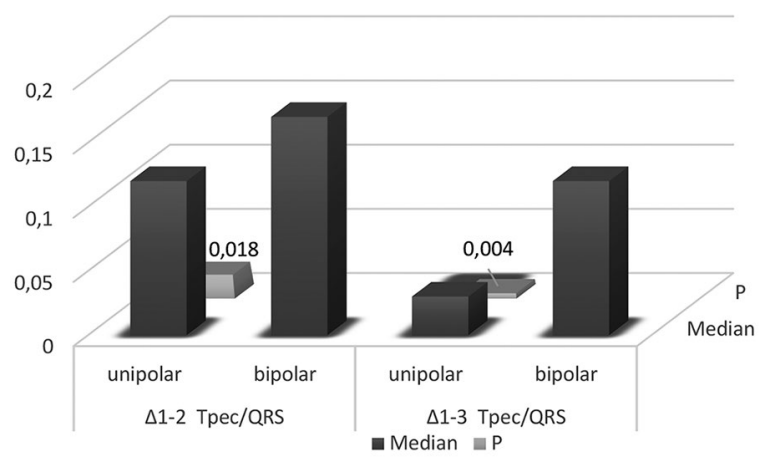

Figure 2. The acute and long-term difference of CRT's impact on Tpec/QRS according to left ventricular pacing polarity.

${ }^{*} \Delta 1-2$ : Change between before and after the procedure (within $48 \mathrm{~h}$ ); $\Delta 1-3$ : Change between before and long term after the procedure (at 6 month); Tpec - TpTe interval corrected according to the Bazzet formula. 


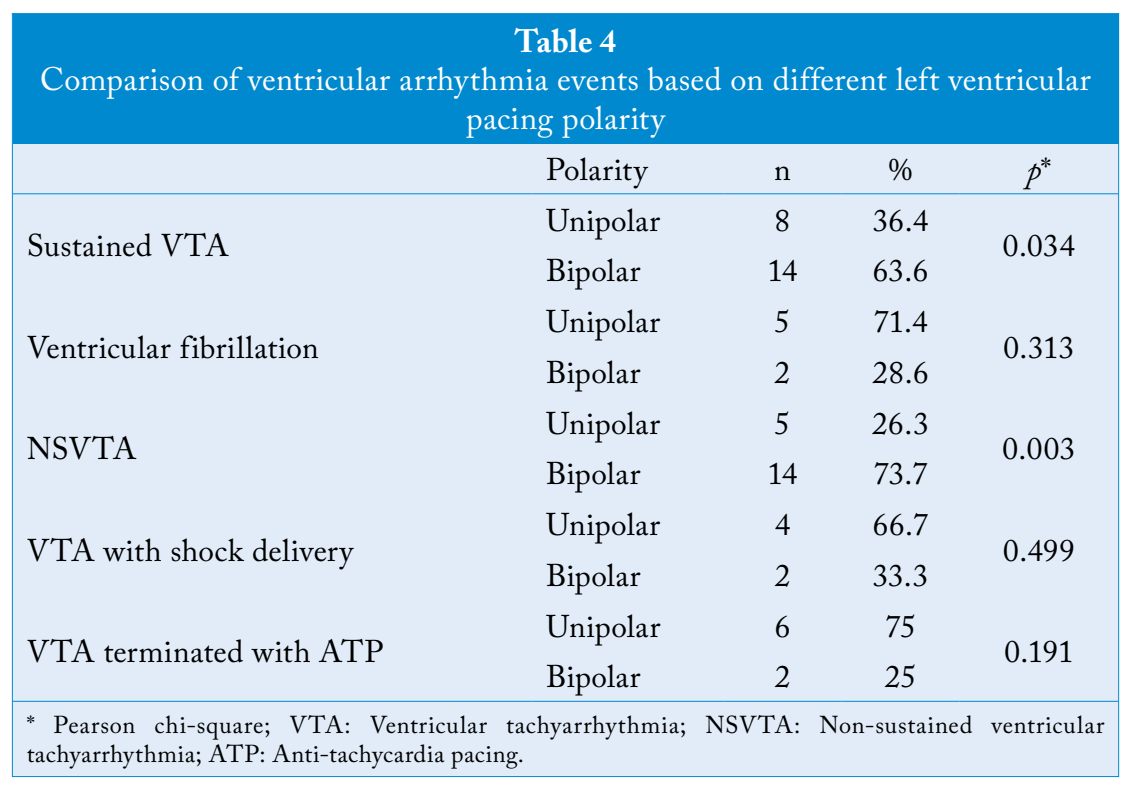

was no significant difference between the two groups in respect of shock delivery and ATP ( $p=0.499$ and $\mathrm{p}=0.191$, respectively). A comparison of ventricular arrhythmias between the groups is summarized in Table 4. Electrical storm was observed in five (9.25\%) patients, including four in the bipolar group and one in the unipolar group. Four of them (80\%) occurred within the first 100 days.

\section{DISCUSSION}

The CRT considered a crucial treatment modality for HF may be pro-arrhythmic, since pacing from epicardium increases TDR. ${ }^{[7]}$ In responders to CRT, this early increase has been shown to decrease in the long-term, presumably as a result of reverse remodeling. ${ }^{[12]}$ In the present study, our objective was to investigate the impact of CRT on conventional and recently defined ventricular repolarization parameters from the perspective of different $L V$ pacing polarities in both acute and long-term and to examine novel arrhythmia predictive parameters taking depolarization into account. We also attempted to identify whether there were reflections on arrhythmic events.

Different pacing polarities lead to different distribution of activation in the ventricle. The activation wave of a bipolar depolarization detracts with the third force of the distance, while a unipolar wave attenuates with the square of the distance. ${ }^{[13]}$ This difference caused by polarity particularly influences the initiation of the re-entry mechanism in the scar tissue. Although the first capture point in the epicardium can be the same, the subepicardial layers captured by the virtual electrode may differ. Additionally, the presence of scar tissues may affect the conduction vectors and can change the transmural activation sequence within such heterogeneous myocardium. ${ }^{[14]}$ Yang et al. ${ }^{[5]}$ reported a higher basal endocardial strain with bipolar pacing and found more uniform global strain compared to unipolar pacing. They also revealed that there were differences in the mechanical activation sequence in terms of $\mathrm{LV}$ pacing polarity, probably affecting vectoral activation and ventricular repolarization patterns.

Myocardial activation sequence reverses during biventricular pacing in conventional CRT patients. As a consequence of this reverse activation, early repolarization of epicardium, delayed activation and repolarization of midmyocardial $M$ cells lead to a significant increase in TDR. ${ }^{[7]}$ The Increased TDR can be measured non-invasively using parameters, such as Tpeak-Tend (TpTe or Tpe) and Tp-Te/QT. ${ }^{[15]}$ Furthermore, it was shown that the $\mathrm{QT}$ dispersion which reflects regional heterogeneity in myocardial repolarization is associated with life-threatening arrhythmias and SCD. However, TpTe has been demonstrated to be superior to QT and QT dispersion in predicting $\mathrm{VTs}^{\left[{ }^{[16]}\right.}$ The TDR seems to play a key arrhythmogenic role not only in CRT's HF patients, but also in those with SCD, myocardial infarction, long QT syndrome, and Brugada syndrome. ${ }^{[17]}$ Recently, 
Tpec (TpTe corrected according to the Bazett formula) was suggested to be more sensitive measurement in predicting the risk of SCD and Tpec of more than $90 \mathrm{msec}$ was determined to be associated with an approximately three-fold increased risk. ${ }^{[18]}$ In the light of these data, we investigated both Tpec and Tpec/QTc value that, to the best of our knowledge, has not been evaluated previously.

In our study, Tpec/QTc showed a significant postprocedural increase in the true bipolar group, while a decrease was observed in the unipolar/extended bipolar group. The difference between the two groups decreased in the long-term, but remained statistically significant. There was no significant difference in the remaining ventricular repolarization parameters between the groups. As a clinical reflection of this observation, four of five patients with electrical storm were in the true bipolar LV configuration. Sustained and NSVTs were observed more frequently in the bipolar group. The greater influence of Tpec/QTc in the early period after CRT supports that a significant part of the increase in TDR is temporal. The point that draws our attention in this regard is that electrical storm occurred in four (80\%) of our five patients within the first 100 days.

In another aspect, TDR does not take into account depolarization and action potential in HF patients whose myocardium are electrically and mechanically heterogeneous and transmural activation sequence is abnormal due to scar tissues. Recently, it has been suggested that, in arrhythmogenic right ventricular dysplasia and Brugada syndrome, QT/QRS ratio defined as cardiac electrophysiological balance index can be used to predict arrhythmia, as it takes depolarization into consideration. ${ }^{[19]}$ In this context, it was recommended that $\mathrm{TpTe} / \mathrm{QRS}$ and $\mathrm{TpTe} /(\mathrm{QRS} \times \mathrm{QT})$ parameters may be used, since the TpTe interval has been shown to be more precise in predicting arrhythmic risk rather than the QT interval. ${ }^{[20]}$ In the present study, we evaluated Tpec/QRS and Tpec/(QTc $\times$ QRS) as well as aforementioned novel markers. To the best of our knowledge, this was not previously evaluated in CRT patients.

The LV pacing polarity has also a substantial role in the pathophysiology of arrhythmogenesis other than TDR. Asvestas et al., ${ }^{[21]}$ in a patient who presented with a monomorphic electrical storm two years after CRT, completely terminated the storm by changing the LV pacing configuration from the true bipolar to the extended bipolar (unipolar). The authors suggested that the bipolar configuration (D1-M2) caused the initiation of the one-way block and re-entry circuit due to its proximity to the critical isthmus in the scar tissue, and they prevented the onset of the re-entry circuit by pacing from extended bipolar. Considering the novel arrhythmia markers along with depolarization and TDR in our study, we observed that, in the bipolar group, where electrical storm and sustained VTAs were predominantly observed, the TpTe/QRS, Tpec/ QRS, Tpec/QRS $\times$ QTc, TpTe/QRS $\times$ QTc values increased more than the unipolar group. We persuaded that these markers may be used to predict arrhythmia, if supported by larger studies.

The main limitation of the present study is its relatively small sample size. The second limitation is the relatively high ischemic etiology (44.4\%). The presence of ischemic scar tissues, as well as the heterogeneity of myocardium may have influenced the transmural activation sequence and VTAs. However, it should be kept in mind that the CRT patient population in daily practice is quite heterogeneous, as in this study. Bias in choosing the LV pacing configuration can be also considered a limiting factor; many factors, such as the branch of the existing CS, the risk of phrenic nerve stimulation, avoiding anodal capture, and optimization of $\mathrm{LV}$ pacing thresholds are taken into consideration in the decision-making process. Furthermore, given the nature of the study, we cannot ignore the impact of extrinsic and intrinsic variables, such as use of antiarrhythmic agents, coronary anatomy, and LV lead position on the outcomes.

In conclusion, left ventricular pacing polarity significantly affects Tpec/QTc, but not other ventricular repolarization parameters. Novel arrhythmia predictors $(\mathrm{TpTe} / \mathrm{QRS}, \mathrm{Tpec} / \mathrm{QRS}, \mathrm{TpTe} /(\mathrm{QRS} \times \mathrm{QTc})$ and $\mathrm{Tpec} /(\mathrm{QRS} \times \mathrm{QTc}))$ are more influenced in bipolar pacing associated with more frequent ventricular tachyarrythmias.

\section{Declaration of conflicting interests}

The authors declared no conflicts of interest with respect to the authorship and/or publication of this article.

\section{Funding}

The authors received no financial support for the research and/or authorship of this article. 


\section{REFERENCES}

1. Ponikowski P, Voors AA, Anker SD, Bueno H, Cleland JGF, Coats AJS, et al. 2016 ESC Guidelines for the diagnosis and treatment of acute and chronic heart failure: The Task Force for the diagnosis and treatment of acute and chronic heart failure of the European Society of Cardiology (ESC). Developed with the special contribution of the Heart Failure Association (HFA) of the ESC. Eur Heart J 2016;37:2129-200.

2. Auricchio A, Stellbrink C, Block M, Sack S, Vogt J, Bakker $P$, et al. Effect of pacing chamber and atrioventricular delay on acute systolic function of paced patients with congestive heart failure. The Pacing Therapies for Congestive Heart Failure Study Group. The Guidant Congestive Heart Failure Research Group. Circulation 1999;99:2993-3001.

3. Blanc JJ, Etienne Y, Gilard M, Mansourati J, Munier S, Boschat J, et al. Evaluation of different ventricular pacing sites in patients with severe heart failure: Results of an acute hemodynamic study. Circulation 1997;96:3273-7.

4. Seifert M, Schau T, Moeller V, Neuss M, Meyhoefer J, Butter C. Influence of pacing configurations, body mass index, and position of coronary sinus lead on frequency of phrenic nerve stimulation and pacing thresholds under cardiac resynchronization therapy. Europace 2010;12:961-7.

5. Yang HS, Caracciolo G, Sengupta PP, Goel R, Chandrasekaran K, Srivathsan K. Pacing polarity and left ventricular mechanical activation sequence in cardiac resynchronization therapy. J Interv Card Electrophysiol 2012;35:101-7.

6. Fish JM, Di Diego JM, Nesterenko V, Antzelevitch C. Epicardial activation of left ventricular wall prolongs QT interval and transmural dispersion of repolarization: Implications for biventricular pacing. Circulation 2004;109:2136-42.

7. Medina-Ravell VA, Lankipalli RS, Yan GX, Antzelevitch C, Medina-Malpica NA, Medina-Malpica OA, et al. Effect of epicardial or biventricular pacing to prolong QT interval and increase transmural dispersion of repolarization: Does resynchronization therapy pose a risk for patients predisposed to long QT or torsade de pointes? Circulation 2003;107:740-6.

8. Mykytsey A, Maheshwari P, Dhar G, Razminia M, Zheutlin $\mathrm{T}$, Wang $\mathrm{T}$, et al. Ventricular tachycardia induced by biventricular pacing in patient with severe ischemic cardiomyopathy. J Cardiovasc Electrophysiol 2005; 16:655-8.

9. Gold MR, Linde C, Abraham WT, Gardiwal A, Daubert JC. The impact of cardiac resynchronization therapy on the incidence of ventricular arrhythmias in mild heart failure.
Heart Rhythm 2011;8:679-84.

10. Jamé S, Kutyifa V, Aktas MK, McNitt S, Polonsky B, Al-Ahmad A, et al. Bipolar left ventricular pacing is associated with significant reduction in heart failure or death in CRT-D patients with LBBB. Heart Rhythm 2016;13:1468-74.

11. Göçer H, Durukan AB, Naseri E, Ünal M. Determination of acute changes in new electrocardiography parameters during veno-venous extracorporeal membrane oxygenation support. Kardiochir Torakochirurgia Pol 2020;17:189-92.

12. Itoh M, Yoshida A, Fukuzawa K, Kiuchi K, Imamura K, Fujiwara R, et al. Time-dependent effect of cardiac resynchronization therapy on ventricular repolarization and ventricular arrhythmias. Europace 2013;15:1798-804.

13. Durrer D, Van Der Twell LH. Spread of activation in the left ventricular wall of the dog. I. Am Heart J 1953;46:683-91.

14. Soejima K, Stevenson WG, Maisel WH, Sapp JL, Epstein LM. Electrically unexcitable scar mapping based on pacing threshold for identification of the reentry circuit isthmus: Feasibility for guiding ventricular tachycardia ablation. Circulation 2002;106:1678-83.

15. Barbhaiya C, Po JR, Hanon S, Schweitzer P. Tpeak - Tend and Tpeak - Tend /QT ratio as markers of ventricular arrhythmia risk in cardiac resynchronization therapy patients. Pacing Clin Electrophysiol 2013;36:103-8.

16. Shimizu $M$, Ino $H$, Okeie $K$, Yamaguchi $M$, Nagata $M$, Hayashi $\mathrm{K}$, et al. T-peak to T-end interval may be a better predictor of high-risk patients with hypertrophic cardiomyopathy associated with a cardiac troponin I mutation than QT dispersion. Clin Cardiol 2002;25:335-9.

17. Panikkath R, Reinier K, Uy-Evanado A, Teodorescu C, Hattenhauer J, Mariani R, et al. Prolonged Tpeak-to-tend interval on the resting ECG is associated with increased risk of sudden cardiac death. Circ Arrhythm Electrophysiol 2011;4:441-7.

18. Chua KC, Rusinaru C, Reinier K, Uy-Evanado A, Chugh H, Gunson $\mathrm{K}$, et al. Tpeak-to-Tend interval corrected for heart rate: A more precise measure of increased sudden death risk? Heart Rhythm 2016;13:2181-5.

19. Agullo-Pascual E, Cerrone M, Delmar M. Arrhythmogenic cardiomyopathy and Brugada syndrome: Diseases of the connexome. FEBS Lett 2014;588:1322-30.

20. Tse G. (Tpeak - Tend)/QRS and (Tpeak - Tend)/(QT $\times$ QRS): Novel markers for predicting arrhythmic risk in the Brugada syndrome. Europace 2017;19:696.

21. Asvestas D, Balasubramaniam R, Sopher M, Paisey J, Babu GG. Extended bipolar left ventricular pacing as a possible therapy for late electrical storm induced by cardiac resynchronization therapy. J Electrocardiol 2017;50:349-52. 